\title{
SERUM N-TERMINAL PRO BRAIN NATRIURETIC PEPTIDE LEVEL IN PATIENTS WITH PROLACTINOMA WHO WERE TREATED WITH CABORGOLINE
}

\author{
Dr.Mustafa Tasdelen ${ }^{1}$, Dr.Senay Arıkan Durmaz², Dr.Nesligul Yıldırım³, Dr.Eyup Koc4
}

${ }^{1}$ Kirikkale University Faculty Of Medicine , Department of Internal Medicine ,Kirikkale, Turkey. ${ }^{2}$ Kirikkale University Faculty Of Medicine, Department of Endocrinology, Kirikkale, Turkey

${ }^{3}$ Kirikkale University Faculty Of Medicine, Department of cardiology, Kirikkale, Turkey

4 Kirikkale University Faculty Of Medicine, Department of Nephrology ,Kirikkale, Turkey.

\section{Introduction}

Cabergoline, a long-lasting dopamine-agonist, is generally considered to be the safety drug for the treatment of prolactinoma. But, use of long time and high dose cabergoline may be a cause of cardiac valvulopathy in patient with prolactinoma. In present study, we aim to determine serum Nterminal probrain natriuretic peptide levels in patients with prolactinoma who were treated with cabergoline.

\section{Method}

Thirty patients with prolactinoma who applied to our endocrinology outpatient clinic (mean age $33.4 \pm 8.5$ years and body mass index (BMI): $28.1 \pm 7.8 \mathrm{~kg} / \mathrm{m}^{2}$ ), 30 age- and BMI matched (mean age 30.0 \pm 9.8 years; BMI: $26.8 \pm 6.4 \mathrm{~kg} / \mathrm{m}^{2}$ ) patients who were determined another cause of hyperprolactinemia except prolactinoma, and age- and BMI matched healthy individuals (mean age 31.0 37.0 years; BMI: $25.2 \pm 2.9 \mathrm{~kg} / \mathrm{m}^{2}$ were included in the study. Cumulative cabergoline dose was calculated in patients with prolactinoma who have received prior cabergoline therapy. Anthropometric measurements were performed. Blood pressure was measured in accordance with its thecnic. Serum samples for NT-pro BNP levels were stored $-20{ }^{\circ} \mathrm{C}$. All biochemical and hormonal analysis were performed by automatic analyzer.

\section{Results}

We found that serum NT-pro BNP levels were not significantly different between study groups $(63.9 \pm 39.8 \mathrm{pg} / \mathrm{ml}$ in prolactinoma group, $47.3 \pm 31.2 \mathrm{pg} / \mathrm{ml}$ in hyperprolactinemia group and $57.2 \pm$ $28.3 \mathrm{pg} / \mathrm{ml}$ in control group, $\mathrm{p}=0.160$ ). Mean cumulative cabergoline dose (CCD) were calculated as 218.1 \pm 252.5 (range 52-1248 mg). However, we did not determine any correlations between serum NT-pro BNP levels and cumulative cabergoline dose, and between serum NT-pro BNP and prolactine levels. There was only a positive correlation between CCD and systolic blood tension $(r=0.213, p=0.044)$.

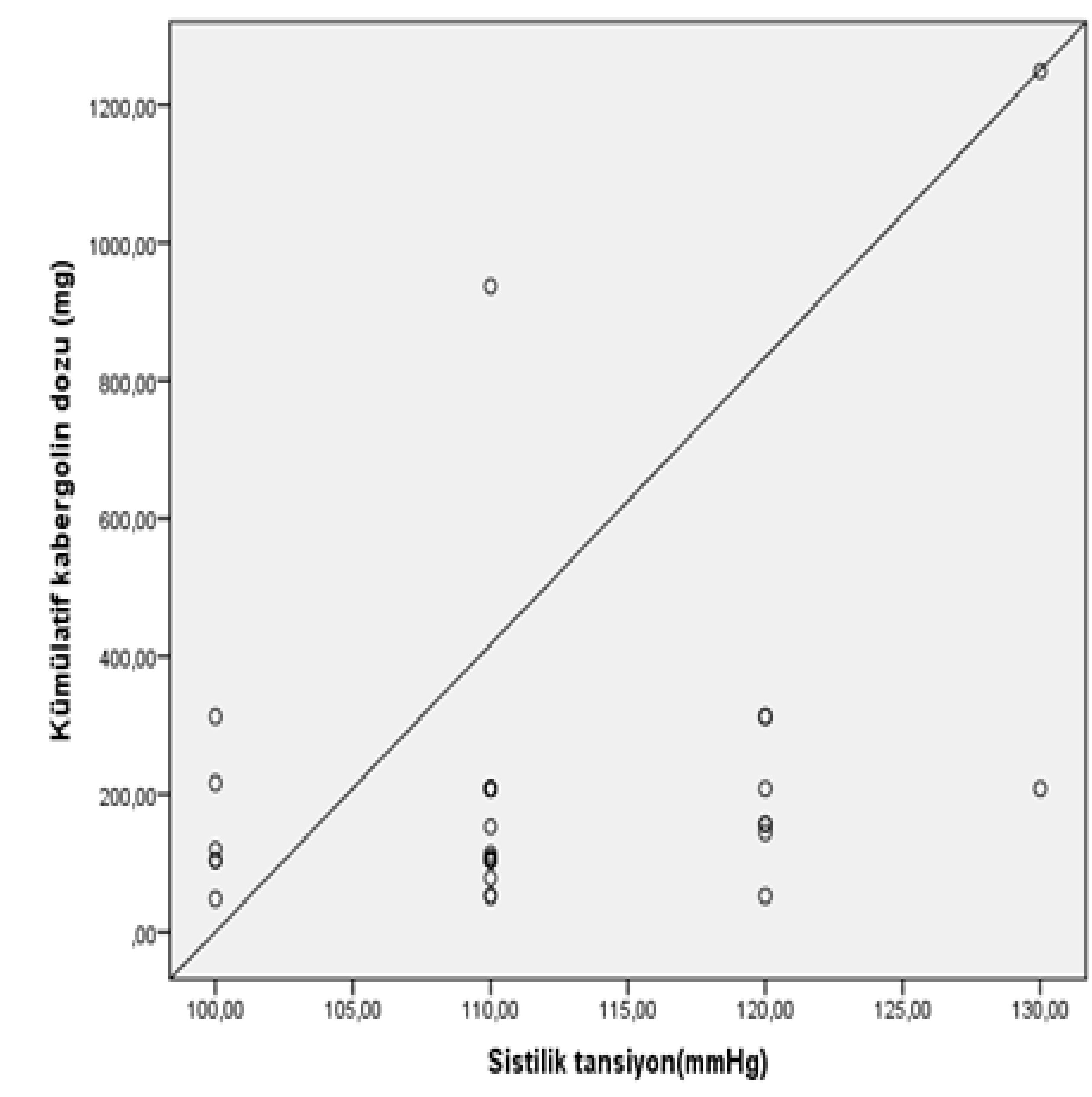

\section{Conclusions}

According to our findings, cabergoline treatment does not influence serum NT-pro BNP levels in prolactinoma patients. Advanced studies which were included more patients with prolactinoma need to clarified this topic. 